\title{
COVID-19 Pandemic Impact on the Performance of Educational Process: From Khyber Pakhtunkhwa Student
}

\author{
${ }^{a}$ MinhajUllah, ${ }^{b}$ Shakeel Khan, ${ }^{c}$ Bushra Hamid, d Afifa Anjum Khattak \\ a Institute of Management Studies, University of Peshawar, Pakistan \\ Email: minhajpeshawar@gmail.com \\ ${ }^{\mathrm{b}}$ Institute of Management Studies, University of Peshawar, Pakistan \\ Email: shakeel.ims@uop.edu.pk \\ c Institute of Management Studies, University of Peshawar, Pakistan \\ Email: dean_ims@uop.edu.pk \\ ${ }^{\mathrm{d}}$ Institute of Management Studies, University of Peshawar, Pakistan \\ Email: affifaims@gmail.com
}

\begin{tabular}{l}
\hline ARTICLE DETAILS \\
\hline History: \\
Accepted 30 July 2021 \\
Available Online September 2021 \\
\hline Keywords: \\
Newly Merged District, COVID-19 \\
Pandemic, Khyber Pakhtunkhwa, \\
Student Survey, Online \\
Platforms, Quality of Educational \\
Process
\end{tabular}

\section{JEL Classification:} I21, $P_{36}$

DOI: $10.47067 /$ real.v4i3.186

\section{ABSTRACT}

The following research paper emblazons the impact of COVID-19 pandemic on the education sectors of Khyber Pakhtunkhwa University and Colleges students. Data has been collected through Google form, (due to COVID-19 SOP's) from students. Research Population includes 568 students from different universities programmes and semesters that have presented their views about effect of study in COVID-19 Pandemic. The overall output of the survey highlighted that majority of students were not aware about the digital tools, which they are now apprised of, which according to them will help them in the future career. Majority of the students negate the online classes due to, lack of resources, time issues and no internet facility or the students that devoid of any practical work repealed it. Main problem that has been highlighted is Internet connection problem in newly merged District of Khyber Pakhtunkhwa. Lack of a satisfactory substructure, learning motivation, socialization for majority students, hindrances to perform practical applications, less effective student-teacher interaction and communication, less achievements of the examination objective, online examination e.g., lack of two way communication, more chances of cheating, possibility of mental health and physical deprivation (e.g., spending too much time in front of screens, installation of a deskbound routine. Therefore communication for the contemporary academic year, effective and efficient measures have to be imposed by the university management to solve all the students' issues (internet issues and relevant data availability) and waive off as much as possible these undesirable issues and to develop a better online education process.

(C) 2021 The authors. Published by SPCRD Global Publishing. This is an open access article under the Creative Commons AttributionNonCommercial 4.0 


\section{Introduction}

Education is "a fundamental human right, a global common goal and a primary driver of progress across all the 17 Sustainable Development Goals (SDG) of the 2030 Agenda as a bedrock of just, equal, inclusive, peaceful societies". With the current COVID-19 pandemic, labelled as a "Dark

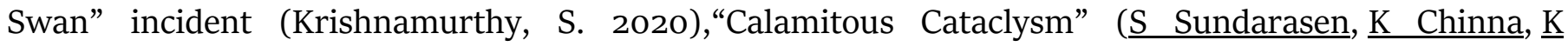
Kamaludin, 2020), and compared to the World War II in terms of economic and societal consequences [Nicola, M., Alsafi, Z., Sohrabi, at all, 2020), Staszkiewicz, P., Chomiak-Orsa, I., \& Staszkiewicz, I. (2020) Which has the largest interruption in the history especially on education, and has already had a near worldwide impact on teachers and learners around the globe (Aziz, Hassan , 2021) (SZ Zhao, JYH Wong, Y Wu, EPH Choi, 2020), \& Ebner, M.; Schon, S.; Braun, 2020).

Pakistan Imposed lockdown as a response to COVID-19 pandemic, by March 13 (Friday), 2020 all educational institutes were closed for the three weeks across the country on emergency shutdown order, "It has been decided to close all educational institutions in the country till April 5," (Derived from aa.com, BBC.pk, \& Dawn News, 2020). The lockdown was lifted on May 9, 2020. Since June 16, 2020 restricted lockdown was forced in specific areas, (Maryam Akmal, Lee Crawfurd, Susannah Hares, and Ana Luiza Minardi, 2020).

The advancement in technology and declining prices of gadgets specially the mobile phones have given ease of access and usage to many households in Pakistan. According to (Shahid Hussian, 2018) in Pakistan both the rural and urban population had access to mobile phones, laptops and other such gadgets and due to better internet facilities they abandoned going to net cafes as they had the access at homes. However, it is easy to access, the views about the prices of internet packages and use of the gadgets for DL (distance learning) still exists among the varying social Classes of Pakistan. According to (Maryam Akmal, 2020) only 47\% make a positive use of technology and use it for the online classes. The access to gadgets and technology might have helped DL and strengthened the infrastructure required but the use of these facilities for DL under covid-19 pandemic is still an area to be explored.

The environment, students are confined to influence the learning process, the facts that make the environment conducive, enhances engagement among students and hence the learning (Shernoff, 2016) During pandemics such as Covid-19 the physical environment required for learning is disrupted however the decline in engagement is yet to be uncovered as the use of different gadgets and techniques might have enhanced engagement. Moreover according to (Maryam Akmal, 2020) two-third of respondents indicated that they had the required help at home Watermeyer, R., Crick, T., Knight, C., \& Goodall, J. (2020).

\section{Literature Review}

The pandemics like Covid-19, impacts all walks of life, including, economic, developmental and financial activities, the most affected region of Pakistan, southern Sindh initiated the closure of institutions until 3oth May which was then followed by the state. On State level decision was taken to close all kinds of educational institutions till $5^{\text {th }}$ April. To protect the country against the spread of virus and its consequences the adjoining borders were also closed. (Sajid, 2020)

The closure of institutions was continued, till late November. In June the private institutes' association; All Pakistan Private Schools Federation (APPSF) emphasized on opening of institutes as they were losing their livelihood and the education of students was impacted, they emphasized on playing with schedule and calling students in groups, following the required SOPs to reduce the threat 
of spread. The suggestions were rejected by the education Minister, Punjab Mr. Rass, who focused on the lives of students. (Reporter, 2020).

Experienced teachers give close consideration to their students, changing their encouraging when students appear to be lost. This unique collaboration is absent in online education. We conjectured that mindful students follow recordings likewise with their eyes. In this manner, regard for educational recordings could be evaluated distantly by following eye developments. Here we show that inter subjective connection of eye developments during video show is significantly higher for mindful students and that synchronized eye developments are prescient of individual grades on the material introduced in the video. These discoveries recreate for recordings in an assortment of creation styles, for accidental and deliberate learning and for review and perception questions the same. We replicate the outcome utilizing standard web cameras to catch eye developments in a homeroom setting and with more than 1,000 members at home without the need to communicate client information. Our outcomes propose that online education could be made versatile to a student's degree of consideration progressively (Madsen, Jens, 2021)

With reopening of educational institutes, the surge in corona virus cases was prominent which made the education minister, Shafqat Mehmood to close the institutes again from $26^{\text {th }}$ November. The Minister accentuated on home learning, the schedule for board examination was also changed and the recommendation was to shift the examination from the month of March, which is the usual period for such exams to, May or June. However, the entrance exams were permitted as they can be conducted under the required SOPs (Dawn.com, 2020)

During all this period and chaos, the focus was on the continuity of online education despite the limited resources or the novelty of the concept. The advancement in technology and declining prices of gadgets specially the mobile phones have given ease of access and usage to many households in Pakistan, According to (Shahid Hussian, 2018)in Pakistan both the rural and urban population had access to mobile phones, laptops and other such gadgets and due to better internet facilities they abandoned going to net cafes as they had the access at homes. Though it is easy to access, the views about the prices of internet packages and use of the gadgets for DL (distance learning) still exists among the varying social Classes of Pakistan. According to (Maryam Akmal, 2020) only 47\% make a positive use of technology and use it for the online classes. The access to gadgets and technology might have helped DL and strengthened the infrastructure required but the use of these facilities for DL under covid-19 pandemic is still an area to be explored.

The existing infrastructure often collapses under pandemics; it's a graver challenge for developing countries like Pakistan. The diversity of its population and educational institutions adds to the challenge, there are lucky few who get the chance to online education in a true sense while others must get their selves satisfied with the mere fanciness of the term online learning. Mobile phone penetration is $51 \%$ in Pakistan, but people have better access to television comparatively which urged the state to initiate Tele school, TV channel designated for online learning only. The problem is also of too few resources which might be enough under normal situation but not the pandemics like covid-19, where students must share the gadgets with their siblings and parents. Affordability of internet package is also a misery among individuals who try hard to earn bread.

Covid-19 has however changed the landscape for many countries, including Pakistan, where the interest has been shifted towards e-tech platforms such as Taleemabad app which grew by 660\%, but the question about the gap and variation among the population is still a challenge. (Zahra-Malik, 2020) 


\section{Methadology}

The data is collected through google forms, due to Covid-19 restrictions, data was collected among diverse groups including students belonging to different disciplines, institutions and geographical locations.

\subsection{Survey}

Every educational process local and international has been disrupted due to the COVID-19 pandemic, government and all other organizations try to prevent the spread and infection in the country. Thus, whole world system change within 3 months and the educational departments especially in less developed countries e.g. Pakistan, India, Afghanistan and Bangladesh the staff and also the students were spurred high in the duration of online knowledge, digital inculcation, transmission, and the proper training of the teachers and students with efficiently utilising new technologies in order to achieve the goal of online activities and learning.

The overall main objective of the study is to know the view of Khyber Pakhtunkhwa students regarding the COVID-19 pandemic and online system of the education, given the fact that, up to this level (i.e., Intermediate, bachelor's, master's, MPhil and PhD degree), they have never faced this form of education. The specific resulting objectives we hunted were:

- To determining the capability of the implemented online platforms and know about the existing infrastructure.;

- To know about to which extent teaching staff cope with this challenges and new way of teaching and student evaluation;

- To identify the negative and also positive aspects from the students perspectives and solve all the problem in the COVID-19 that likely to repeat or persist in the future.

\section{Finding}

4.1 Question1-4, are designed to gather the demographic information.

Since, our dataset is composed of ddiverse groups. First few charts that relate to demographic elements such as gender and locality;

\section{Gender}

568 responses

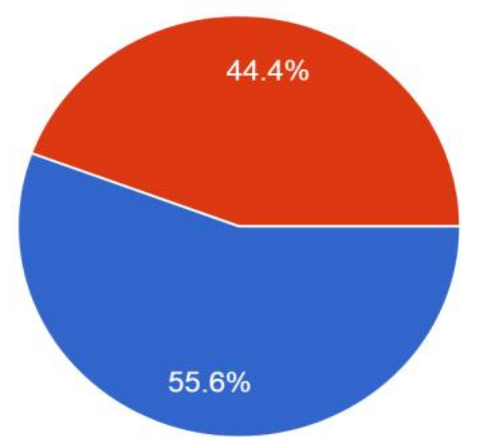


1) Total 568 responses were collected out of which 56\% were males and ( $44 \%$ ) were males.

College / University

568 responses

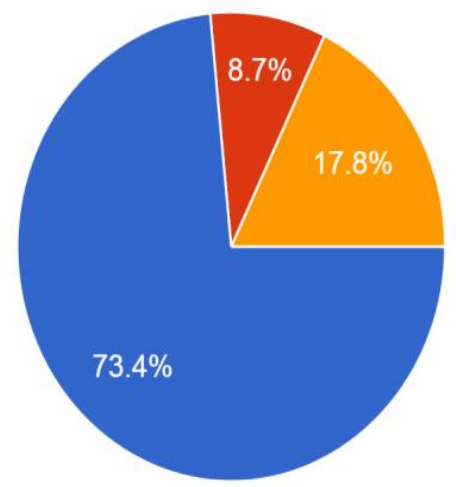

Government

Private

Semi-Government

2) $73.4 \%$ students belonged to government institutions, $8.7 \%$ to private and $17.8 \%$ to semi-government institutions.

\section{Discipline}

568 responses

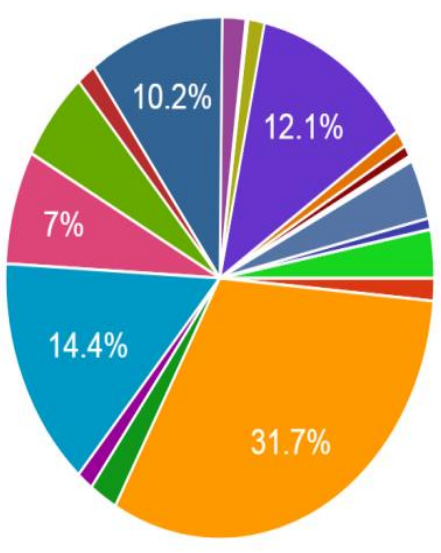

Arabic

Arts \& Design

Business Administration

Public Administration

Commerce

Bio-Technology

Chemistry

Computer Science

$1 / 3 \nabla$

3) Of the responses collected, business administration, public administration, commerce, economics, sociology, social work, statistics, mass communication, development studies were probed. Belonged to social sciences which makes $48.6 \%$ while chemistry, biotechnology, microbiology, maths which belonged to natural sciences made $34.7 \%$. While Computer science, arts and design, Arabic. 
4) $54 \%$ of the respondents belonged to urban area while $46 \%$ belonged to rural areas.

\section{Home City}

568 responses

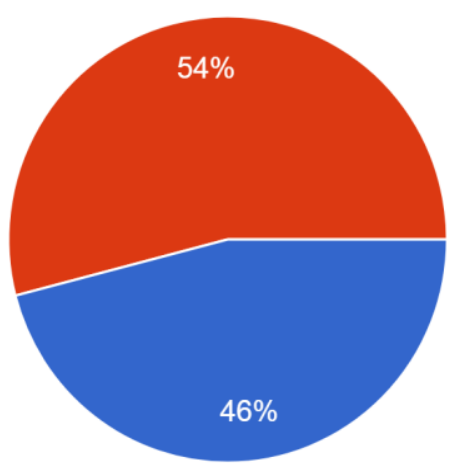

4.2 Questions, 5- 8 were designed to evaluate the efficiency and sufficiency of the existing infrastructure.

5) In order to evaluate the existing infrastructure, we asked about the gadgets required for taking online classes, $53.3 \%$ had the required gadget while $46.7 \%$ hadn't.

Do you have a laptop or a desktop?

568 responses

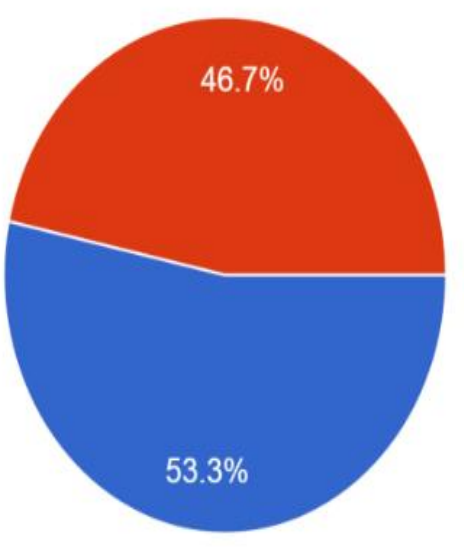


6) A very large chunk of sample had smartphones relative to other gadgets such as laptops or desktops. 94\% respondents had smartphone while 6\% hadn't.

Do you have a smartphone?

568 responses

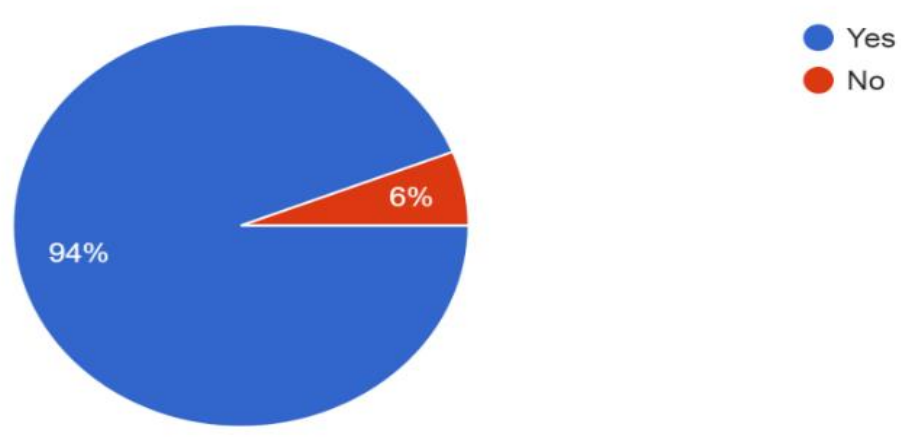

7) To our question about impact of corona virus on studies, $88.7 \%$ said it impacted them while $8.5 \%$ hadn't had any impact while $2.8 \%$ of the respondents were neutral.

Did Corona Pandemic has had impact on your studies?

568 responses

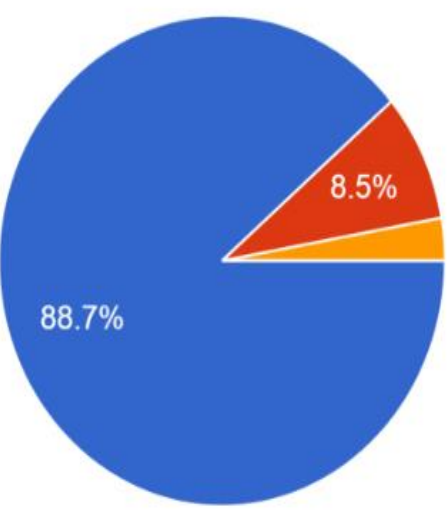

Yes

No

Don't Know 
8) For $72.4 \%$ of the respondents, the impact was negative, $14.1 \%$ were neutral, $7.4 \%$ reported a positive impact and $6.2 \%$ didn't know about it.

They impact was?

568 responses

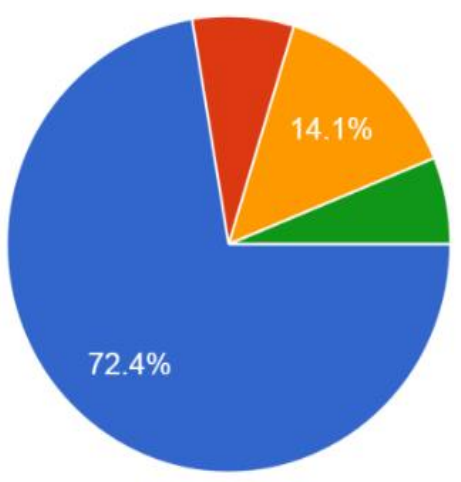

Negative

Positive

Neutral

Don't Know

9) Of the respondents, $67.3 \%$ took online classes, $25.5 \%$ didn't take it regularly and $7.2 \%$ didn't take online classes.

Did you participate in Online Classes?

568 responses
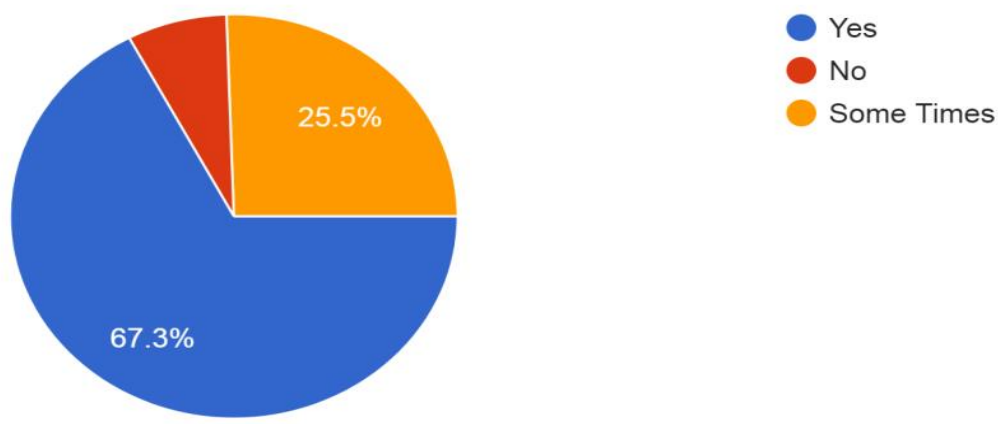

\subsection{Questions, 10-20 measures the efficacy of online classes}

10) $31.2 \%$ reported that online classes were effective to a small extent, $11.6 \%$ to a very small extent, $10.2 \%$ reported the classes were effective to a very large extent, 34\% to a large extent and $13 \%$ reported the classes were completely inefficient. 
To what extend do you consider that the measures taken by your university during COVID19 pandemic to ensure the continuity of the educatio...arning-Assessment) sere sufficient and Effective? 568 responses

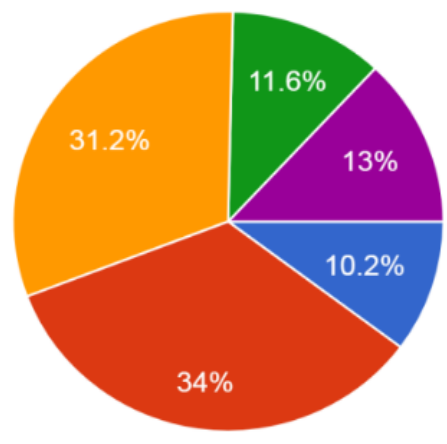

To a very large Extent

To a large Extent

To a small Extent

To a very Small Extent

Totally inefficient

11) $75 \%$ of the respondents used google meet, $46.8 \%$ used google classroom, $0.9 \%$ used skype, $3 \%$ used WhatsApp, 47.5\% used Zoom, 2.1 had own database, 1.6 used none and 5.8 used other applications.

Which tools (online platforms) is using for online learning?

568 responses

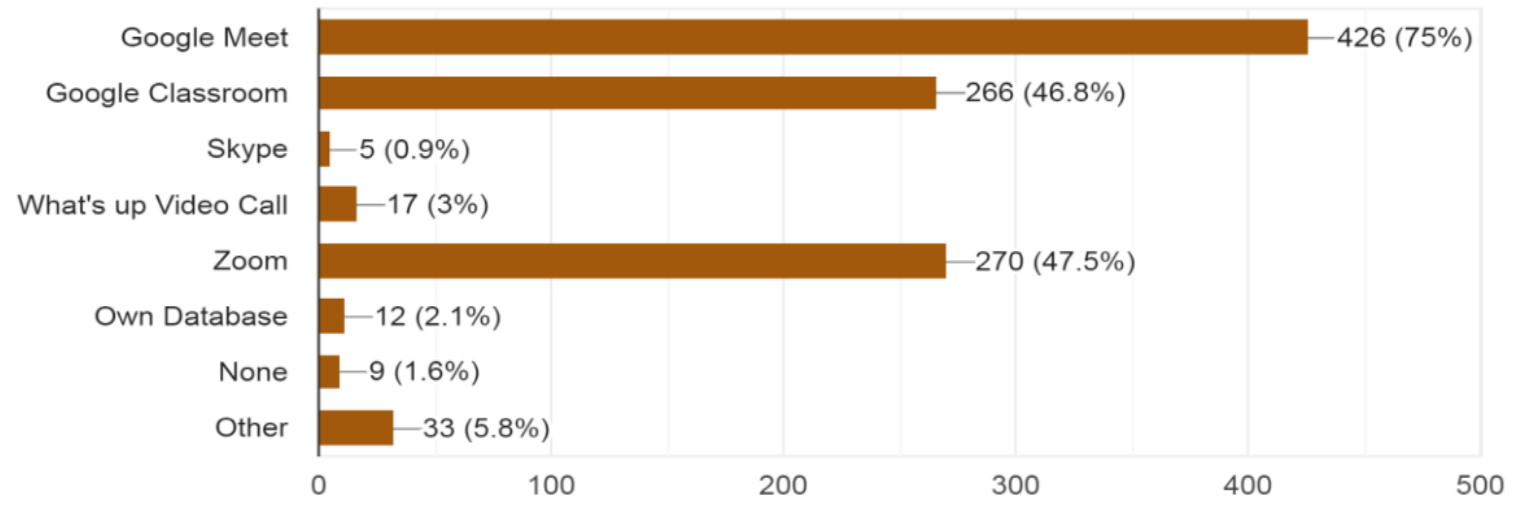

12) $100 \%$ of the respondents had $5.6 \%$ knowledge of such tools before Covid19, $75 \%$ had $7 \cdot 7 \%$ knowledge, $50 \%$ had $48.2 \%$ knowledge, $25 \%$ had $20.1 \%$ knowledge, and $0 \%$ had $48.2 \%$ knowledge of these tools. 
Were you familiar with these online tools, Before Covi-19

568 responses
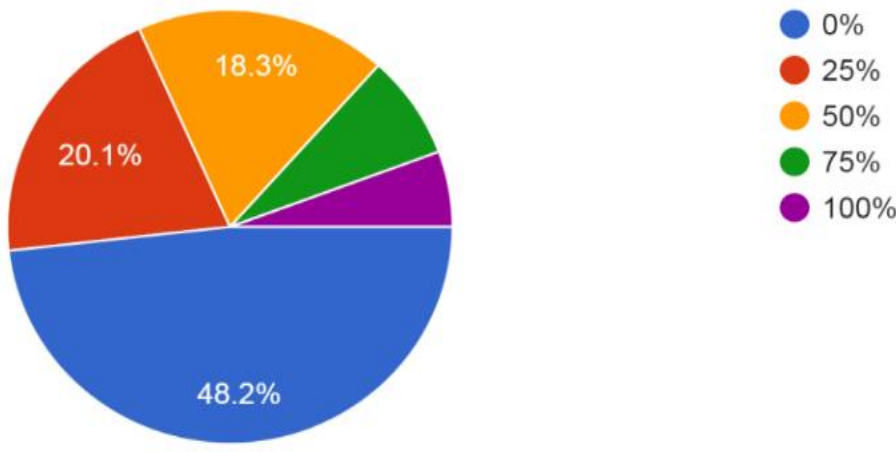

13) Covid-19 has created awareness of such platforms as indicated by the data. $100 \%$ of the respondents had $34.7 \%$ knowledge of such tools before Covid19, $75 \%$ had $28.8 \%$ knowledge, 50\% had $18.1 \%$ knowledge, $25 \%$ had $12 \%$ knowledge, and o\% had 8.5\% knowledge of these tools.

Were you familiar with these online tools, After Covi-19

568 responses

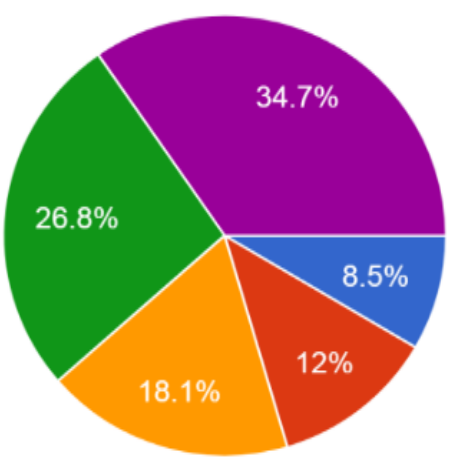

$0 \%$

$25 \%$

$50 \%$

$75 \%$

$100 \%$

14) To measure the experience of online classes six elements were tested, internet connection, availability of equipment, environment for learning, interaction and communication, and quality of overall learning during the class. 
How do take the online teaching learning experience in Covid-19.





15) On question to what extent the perception about online learning has changed due to this pandamic, only $4.4 \%$ recorded much more positive change, 31.2\% recorded positive change, $19.9 \%$ didn't confirm any change, $36.3 \%$ recorded negative change and $8.3 \%$ recorded much more negative change.

What do you think on the online education considering the experience during the COVID-19 pandemic?

568 responses

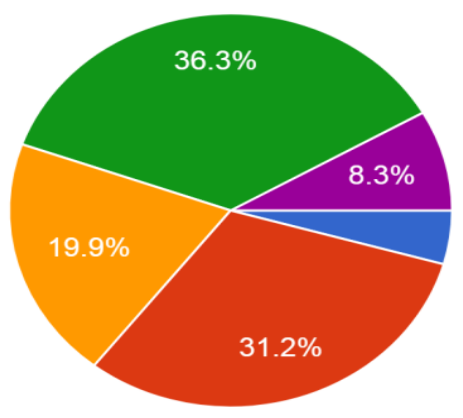

Much More Positive

Positive Change

Not Changed

Negative Change

Much More Negative Change 
16) The advantages are divided in following heads:

- Will help in future career challenges.

- Improved Digital skills for students

- Online meeting

- New innovative tools and material

Main Advantages of online education in future?

568 responses

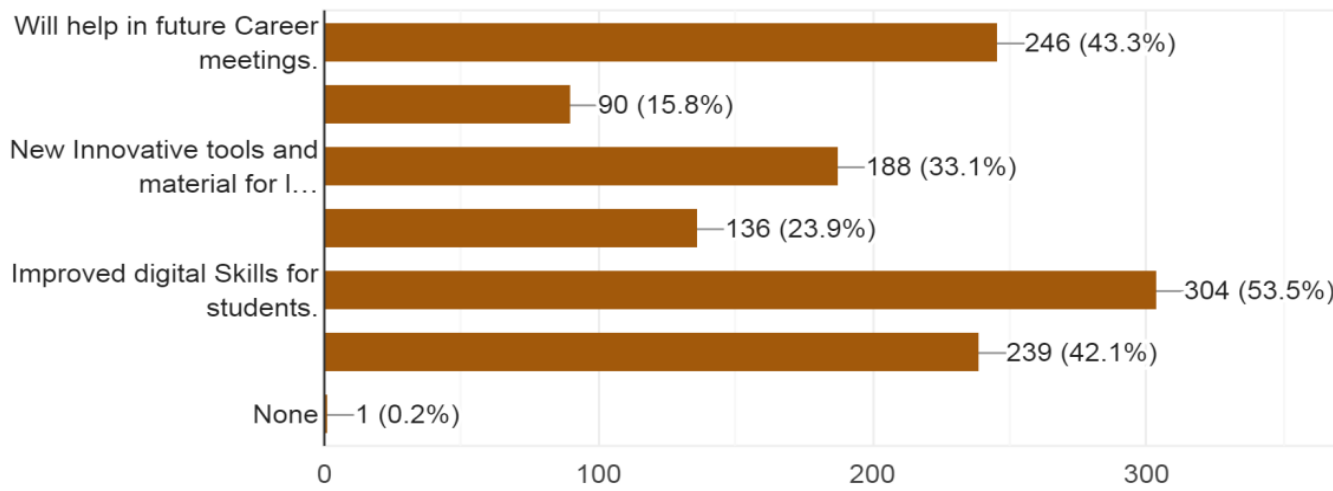

\begin{tabular}{|l|c|}
\hline Advantage & Percentage \\
\hline Helpful in future meetings & $43 \cdot 3 \%$ \\
\hline Flexible learning process & $15.8 \%$ \\
\hline New innovative tools and material & $33.1 \%$ \\
\hline Improved digital skills & $5.5 \%$ \\
\hline Ease of interaction and communication & $23.9 \%$ \\
\hline Technology adoption & $42.1 \%$ \\
\hline None & $0 \%$ \\
\hline
\end{tabular}

17) Level of effort from university is measured around, effort put into the course, into teaching material, into facilities, into study environment.

\begin{tabular}{|l|l|l|l|l|r|}
\hline & Poor & Fair & Satisfactory & $\begin{array}{l}\text { Very } \\
\text { good }\end{array}$ & Excellent \\
\hline Course & $15.06 \%$ & $35.57 \%$ & $30.85 \%$ & $13.25 \%$ & $5.26 \%$ \\
\hline Material & $12.20 \%$ & $39.37 \%$ & $29.21 \%$ & $13.68 \%$ & $5.55 \%$ \\
\hline Facilities & $16.88 \%$ & $34.51 \%$ & $31.73 \%$ & $11.87 \%$ & $5.01 \%$ \\
\hline Study Environment & $20.22 \%$ & $32.06 \%$ & $28.78 \%$ & $14.03 \%$ & $4.92 \%$ \\
\hline
\end{tabular}


18) The skills and responsiveness is measured around following elements, effectiveness of demonstrator, clarity of presentations,simulation of interest, effective usage of time by instructors, availability of instructors, grading and feedback.

\begin{tabular}{|c|c|c|c|c|c|}
\hline Element & Strongly disagree & Disagree & Neutral & Agree & Strongly Agree \\
\hline Effectiveness of lectures & $14.79 \%$ & $27.99 \%$ & $27.46 \%$ & $24.82 \%$ & $4.93 \%$ \\
\hline Clarity of presentations & $17.78 \%$ & $28.52 \%$ & $24.30 \%$ & $25.70 \%$ & $3.70 \%$ \\
\hline Simulated interest & 18.77 & 25.96 & 31.23 & 21.58 & 2.46 \\
\hline Usage of time & 19.01 & 27.64 & 24.12 & 23.77 & 5.46 \\
\hline Instructors were helpful & 17.43 & 26.41 & 21.13 & 27.11 & 7.92 \\
\hline Grading and feedback was prompt & 17.61 & 25.35 & 32.04 & 20.95 & 4.05 \\
\hline
\end{tabular}

Skill and responsiveness of the instructors in all Online Classes

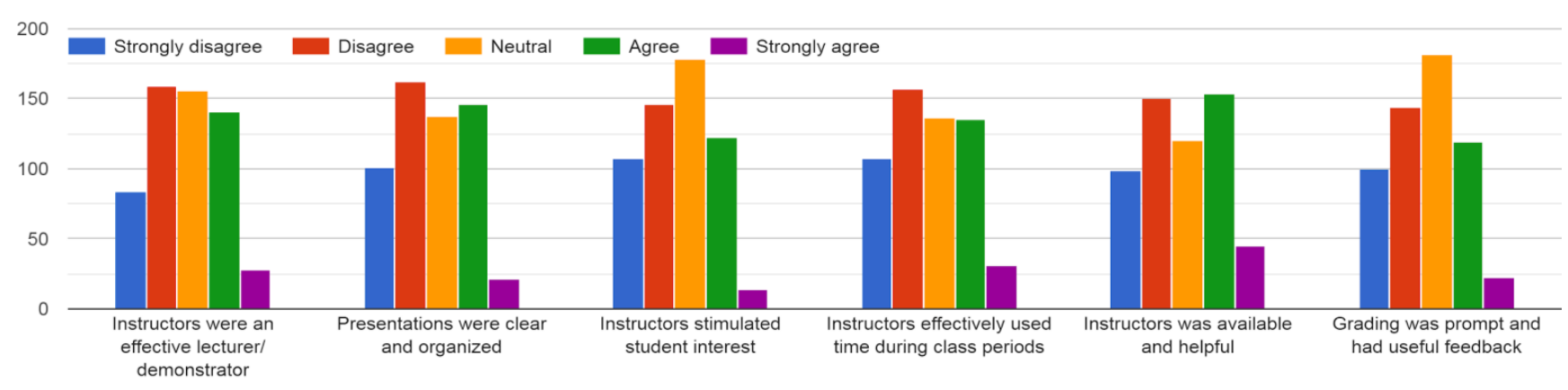

Level of effort from University

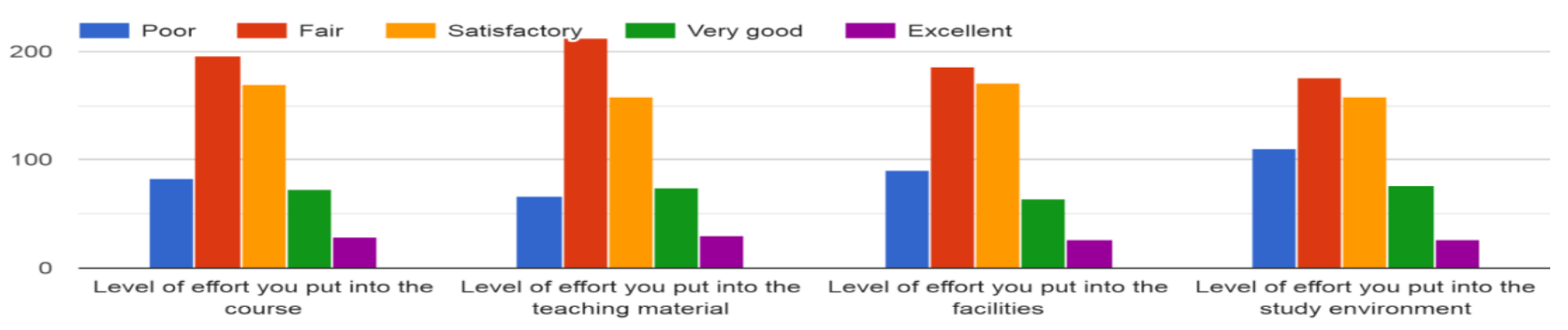

19) The course content was divided around, clarity of learning objectives, planning of course content, workload, student participation.

Over all subject Course content During Covid-19

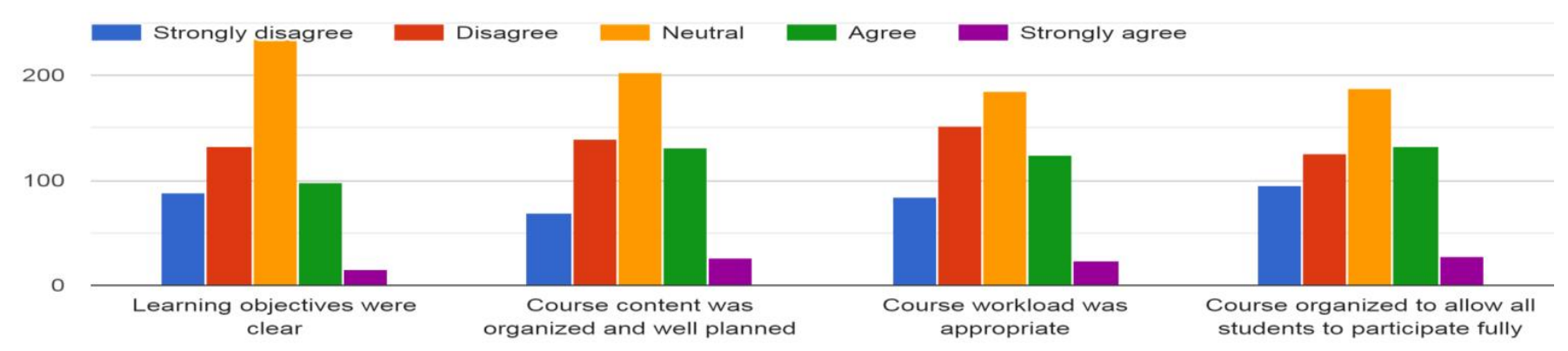




\begin{tabular}{|c|c|c|c|c|c|}
\hline Element( in percentge) & Strongly disagree & Disagree & Neutral & Agree & Strongly Agree \\
\hline Clarity of objectives & 15.49 & 23.42 & 41,20 & 17.25 & 2,64 \\
\hline Content was well planned & 12,15 & 24.47 & 35.74 & 23.06 & 4.58 \\
\hline Workload was appropriate & 14.79 & 26.76 & 32,57 & 21,83 & 4 \\
\hline Allowed student participation & 16.73 & 22,18 & 33.10 & 23.24 & 4 \\
\hline
\end{tabular}

\section{Conclusion}

In this paper, evaluation of 568 students has been done stemming of different public and private sectors educational institutes. The overall result inferred us that majority of the respondents are in a good position to acquire and hold on the gadgets that would be decisive in learning. This also breakdown the segregation of their interest in getting a particular gadget almost a substantial part of the population has good pockets to buy smart phones. This also condone the fact that the usage of smartphones are now very much coincided with the learning Apps i.e. zoom, Google meet, YouTube, What's App and a meager portion to the rest of counterfeit. Students have been now good enough to understand the lectures and are in a cardinal position to slur the presentation antithetical to what would be mainly stuttering during physical in touch. Students (substantial portion) also spilled the beans by penning a good nodding for the teachers and lectures clarity. Online system burgeoned their interest to invigorate their attendance contours.

To say that covid-19 has also deteriorated the archaic educational order would be no understatement there are certain reasons that abysmally rattled the sector that was already reeling to anemic.

- No proper sagacity level on the part of government envisages.

- Stunting funds levels and nose diving in the already meager resources from government subsidies to educational sector.

- Students are very much in-compatible to come out of the primitive classroom espouse.

- Students are mainly unaware of the basic e-learning and are coping with it as pounding the gordien knot.

- The recent stencil of education sector barred the bragging rhetoric voiced a lot by the legislatives.

- Unscrupulous attitudes on part of students, teachers, and management.

- Poor internet and services connections in far flung areas of FATA.

However there are some contemplation required in most of the areas but this doesn't make it marginalized that somehow students and teachers are toiling their best to invigorate the seemingly abysmal conduits between them. The research has been good enough that negating some part of the research population a decisive part has been in a good position and is still doing top notch to toil enough with the contemporary piloted e-infrastructure. And also the parable that rendered a very daunting overture is now in a very burgeon flurry and keeping in view the responses it is very much clear that an enviable sagacity of good opportunities is waiting ahead but this doesn't barred government, legislatives, students and teachers to abeyance their grit and motivation. 


\section{References}

Aziz, H., James, T., Remulla, D., Sher, L., Genyk, Y., Sullivan, M. E., \& Sheikh, M. R. (2021). Effect of COVID-19 on surgical training across the United States: a national survey of general surgery residents. Journal of surgical education, 78(2), 431-439.

United Nations. Policy Brief: Education during COVID-19 and beyond. August 2020. Available online:https://www.un.org/development/desa/dspd/wpcontent/uploads/sites/22/2020/o8/sg_ polcy_brief_covid-19_and_education_august_2020.pdf (accessed on 4 September 2020).

Madsen, J., Julio, S. U., Gucik, P. J., Steinberg, R., \& Parra, L. C. (2021). Synchronized eye movements predict test scores in online video education. Proceedings of the National Academy of Sciences, 118(5).

Krishnamurthy, S. (2020). The Future of Business Education: A Commentary in the Shadow of the Covid-19 Pandemic. Journal of Business Research.

Sundarasen, S., Chinna, K., Kamaludin, K., Nurunnabi, M., Baloch, G. M., Khoshaim, H. B., ... \& Sukayt, A. (2020). Psychological impact of COVID-19 and lockdown among university students in Malaysia: Implications and policy recommendations. International journal of environmental research and public health, 17(17), 6206.

Nicola, M., Alsafi, Z., Sohrabi, C., Kerwan, A., Al-Jabir, A., Iosifidis, C., ... \& Agha, R. (2020). The socioeconomic implications of the coronavirus pandemic (COVID-19): A review. International journal of surgery (London, England), 78, 185.

Staszkiewicz, P., Chomiak-Orsa, I., \& Staszkiewicz, I. (2020). Dynamics of the Covid-19 contagion and mortality: Country factors, social media, and market response evidence from a global panel analysis. Ieee Access, 8, 106009-106022.

Zhao, S. Z., Wong, J. Y. H., Wu, Y., Choi, E. P. H., Wang, M. P., \& Lam, T. H. (2020). Social distancing compliance under Covid-19 pandemic and mental health impacts: A population-based study. International journal of environmental research and public health, 17(18), 6692.

Ebner, M.; Schon, S.; Braun, C.; Ebner, M.; Grigoriadis, Y.; Haas, M.; Leitner, P.; Taraghi, B. Covid-19 epidemic as e-learning boost? Chronological development and effects at an Austrian university against the background of the concept of “e-learning readiness”. Future Internet 2020, 12, 94

Akmal, M., Hares, S., \& O’Donnell, M. (2020). Gendered Impacts of COVID-19 School Closures: Insights from Frontline Organizations.

Derived from: Pakistan closes schools, universities over coronavirus (aa.com.tr)

Derived from: The coronavirus effect on Pakistan's digital divide - BBC Worklife

Maryam Akmal, L. C. (2020). COVID-19 in Pakistan:A Phone Survey to Assess Education, Economic, and Health-Related Outcomes. Center for Global Development .

Shahid Hussian, A. h. (2018). Use of New Media Technologies among Students of Colleges and Universities. PUTAJ - Humanities and Social Sciences, Vol.25 ( No.1-2 ).

Shernoff, D. J. (2016). The influence of the high school classroom environment on learning as mediated by student engagement. School Psychology International.

Dawn.com. (2020, November 23). Dawn . Retrieved from www.dawn.com/news/1591943

Maryam Akmal, L. C. (2020). COVID-19 in Pakistan:A Phone Survey to Assess Education, Economic, and Health-Related Outcomes. Center for Global Development .

Reporter, T. N. (2020, June 3). DAWN . Retrieved from www.dawn.com/news/1560931

Sajid, A. L. (2020, March ). HEALTH, ASIA - PACIFIC,. Retrieved from www.aa.com.tr/en/asiapacific/pakistan-closes..

Shahid Hussian, A. h. (2018). Use of New Media Technologies among Students of Colleges and Universities. PUTAJ - Humanities and Social Sciences, Vol.25 ( No.1-2 ).

Shernoff, D. J., Ruzek, E. A., \& Sinha, S. (2017). The influence of the high school classroom environment 
on learning as mediated by student engagement. School Psychology International, 38(2), 201218.

Watermeyer, R., Crick, T., Knight, C., \& Goodall, J. (2020). COVID-19 and digital disruption in UK universities: Afflictions and affordances of emergency online migration. Higher Education, 1-19.

Zahra-Malik, M. (2020, July 14). BBC. Retrieved from www.bbc.com/worklife/article/20200713-the. 